\title{
ANÁLISE BROMATOLÓGICA DO PÓLEN APÍCOLA DA REGIÃO DO SEMIÁRIDO POTIGUAR
}

Aline Kelly de Souza Melo*; (Graduanda em Licenciatura em Química no Instituto Federal do Rio Grande do Norte, Campus Ipanguaçu - IFRN);

Anna Jacinta Dantas de Medeiros; (Prof ${ }^{a}$. e coordenadora de curso da Licenciatura em Química no Instituto Federal do Rio Grande do Norte, Campus Ipanguaçu - IFRN)

*kelly.aline09@gmail.com

Resumo:

O pólen apícola é formado pela aglutinação do pólen das flores com o néctar e as substâncias salivares das abelhas. Sua composição varia da espécie floral, condição nutricional da planta, clima e região. O pólen apícola tem uma composição química que o constitui como um alimento de rico valor nutricional que traz benefícios para saúde, possuindo carboidratos, lipídeos, proteínas, vitaminas e minerais. No Brasil, sua identidade e qualidade são estabelecidas pelo Ministério de Agricultura e Abastecimento. Tendo o objetivo de avaliar algumas características que fazem do pólen apícola um alimento saudável para consumo humano, foram analisadas as características (cinzas, umidade, proteínas, carboidratos, lipídios e matéria orgânica) de cinco amostras de pólen apícola potiguar. Os teores médios encontrados foram: cinzas $(2,84 \%)$, proteínas (12,95\%), carboidratos (81,45\%), umidade (22,54\%) e lipídeos (2,74\%). O teor de matéria orgânica foi de $97,16 \%$. Das análises realizadas, quase todas estão de acordo com a normativa do Ministério da Agricultura e Abastecimento em sua normativa n ${ }^{\circ} 03$ de 2001 e com estudos de outras regiões, com exceção de carboidratos que se encontrou acima do valor máximo estabelecido (máximo 55\%), resultado que pode ser relacionado a diversidade floral do pólen.

Palavras-chave: Alimento; composição centesimal; qualidade.

\section{I ntrodução}

O pólen, o mel, o própolis e outros produtos de origem apícola, são tradicionalmente utilizados desde muito tempo, especialmente na medicina natural, por apresentar propriedades fitoterápicas e por sua quantidade de nutrientes que possui e vem tomando espaço diante do seu potencial nutricional (MENEZES, 2009).

O pólen apícola é o resultado da agregação do pólen que as abelhas retiram das flores masculinas para formarem seu alimento. São pequenos grãos que se formam nas anteras nos estames da flor, onde é coletado pelas abelhas (MARTINS, 2010). Sua origem depende do tipo de flor em que foi colhido pela abelha (CARPES, 2008).

Ultimamente, o pólen está sendo bastante utilizado, principalmente pelos adeptos aos produtos naturais, como fonte de alimento, servindo como suplemento, por ter em sua composição muitos nutrientes (MENEZES, 2009).

Para o consumo humano, o pólen tem sido reconhecido como uma importante fonte nutricional por apresentar proteínas, carboidratos, lipídios, aminoácidos e minerais em sua composição. Também apresenta substâncias flavonóicas em significativas quantidades (CARPES, 2008).

Faz-se necessário seu estudo nas diversas regiões, visto que o pólen apícola depende do tipo de planta em que foi colhido pela abelha. Este alimento deve satisfazer os critérios de qualidade para a comercialização, já que com o crescente aumento no consumo de produtos naturais, o pólen apícola tem sido usado e comercializado com mais frequência, aumentando também a necessidade no controle de qualidade quanto às características físico-químicas (CARVALHO, 2010).

Desta forma, é imprescindível a análise bromatológica do pólen apícola da região do Semiárido potiguar, uma vez que os trabalhos sobre esse produto são escassos. Assim, é possível conhecer um pouco mais sobre a sua composição e qualidade. 


\subsection{Pólen Apícola}

O pólen é o gameta masculino da flor, tendo a função de fecundar o elemento feminino e reproduzir novos indivíduos da mesma espécie (MARTINS, 2010), sendo formado por pequenos grãos de tamanho aproximado de 6 a $200 \mu \mathrm{m}$, apresenta diversas cores e formatos, podendo possuir alguns poros em sua superfície (ARRUDA, 2009).

Necessário para as abelhas, o pólen apícola pode ser obtido através do uso de coletores de pólen que ficam localizados na entrada das colméias, sendo o resultado da aglutinação do pólen das flores efetuadas pelas abelhas operárias com néctar e suas substâncias salivares (COELHO et al, 2008).

As abelhas recolhem os grãos das anteras de várias flores, acondicionando-os nas corbículas. Em seguida levam para as colméias, depositando nos alvéolos dos favos, onde são usados como alimento para as larvas jovens, devido seus nutrientes, pois constitui fonte de proteínas, gorduras, vitaminas e minerais para as abelhas (RODRIGUES et al, 2013).

Segundo MARCHINI et al (2006) como as abelhas visitam diversas espécies florais para obter o pólen final, as características dele irão depender dessas espécies. Também irão sofrer a influência da idade, da condição nutricional da planta e das condições ambientais durante o desenvolvimento do pólen.

\subsection{Composição Química}

Todos os alimentos de origem apícola têm excelentes propriedades nutricionais (MOURA, 2006). O conhecimento da composição química do pólen apícola se torna essencial para a dieta adequada do indivíduo que o consome (SOUZA et al, 2004).

Devido à importância nutricional e funcional dos componentes contidos no pólen apícola, é importante supervisionar os distintos processos de elaboração, de maneira que se garanta que os alimentos forneçam ao consumidor, todos os nutrientes na sua forma mais disponível, além de cumprir os requerimentos e conservar as propriedades.

Avaliado como um alimento natural, o pólen apícola é saudável e de grande valor nutritivo. Já é reconhecido que as abelhas coletam pólen, por seu alto teor de proteínas (BARTH, 2004). Quase toda a fração protéica está na forma de aminoácidos livres, os quais podem ser assimilados pelo organismo quase imediatamente (HERVATIN, 2009).

De acordo com a Normativa $\mathrm{n}^{\circ} 03$ do MAPA - Ministério da Agricultura e do Abastecimento - (BRASIL, 2001), o pólen deve ter aroma, sabor e cor característicos da origem floral, grãos heterogêneos de tamanhos variados com forma tendendo a esférico, como requisitos.

Os produtos apícolas, pólen e demais, são comercializados com licença do Ministério da Agricultura e tem a inspeção federal evidenciada pelo selo do SIF (Serviço de Inspeção Federal). Estes produtos são vastamente distribuídos ao consumidor para serem alimentos saudáveis e até mesmo de serem complementos nutricionais (MURADIAN, 2000).

Segundo Carpes (2008), a composição do pólen varia da espécie floral, clima, região e estação do ano. Esses fatores são de extrema importância para que o pólen apícola tenha seus valores nutricionais padrão. Cada região geográfica terá suas espécies dominantes de acordo com o clima e o solo que a região oferecer para a produção floral (HERVATIN, 2009).

Os grãos de pólen consistem de uma ampla variedade de moléculas. Estas vão desde biopolímeros de composição em grande parte desconhecidos, à flavonóides e os constituintes das células do interior do pólen, ou seja, proteínas, lipídios, carboidratos e ácido nucléico (SCHULTE et al, 2008). Possui uma grande quantidade de açúcares totais, aproximadamente $40 \%$ (CARPES, 2008).

Para Barreto et al (2012), o pólen tem uma certa quantidade de água, oscilando entre $10 \%$ a $12 \%$, quando fresco, e $4 \%$ para o pólen seco.

As proteínas se encontram com um índice médio de $20 \%$, sendo que uma grande parte está sob forma de aminoácidos livres. Entre os aminoácidos essenciais encontrados no pólen está o ácido aspártico, ácido glutâmico, alanina, arginina, asparagina, cistina, fenilalanina, lisina e outros. (RODRIGUES, 2006). As proteínas são matéria prima para o crescimento adequado dos tecidos, como também é fundamental para sua restauração eficaz (MODRO et al, 2009). 
Vincenzi (2004) afirma que além da proteína, o pólen apícola também contém outros tipos de açúcares, como frutose, dextrina e glicose. Esses são açúcares de fácil absorção pelo organismo.

As fibras se apresentam numa porcentagem que varia entre $3 \%$ a $5 \%$ e os sais minerais com porcentagem variando de 2,5\% a 3,5\% (CARPES, 2008). Já de acordo com Menezes (2009), o teor de cinzas é de 4\%. Como cita Martins (2010), este é um fator que acarreta muitas variações, isso devido a grande diferença à diversidade da flora apícola nas localidades de produção.

O pólen apícola é considerado um alimento rico em sais minerais, como o cobre, magnésio, ferro, cloro, cálcio, iodo, zinco, enxofre, potássio, flúor, entre outros (FERREIRA, 2012).

Segundo a Instrução Normativa n ${ }^{\circ} 03$ do MAPA (2001), para os lipídeos é previsto um valor mínimo de 1,8\% no pólen apícola. O teor de carboidratos deve ser no mínimo de 14\% e um máximo de 55\%. Já as proteínas devem estar presentes numa quantidade mínima de 8\%. Também é citado um valor máximo de 4\% para cinzas e para umidade no pólen seco. Para o pólen fresco, a umidade é estabelecida para um teor de no máximo 30\%.

\section{Metodologia}

As amostras de pólen foram coletadas no apiário experimental do Centro Tecnológico de Apicultura e Meliponicultura do Rio Grande do Norte (CETAPIS), localizado na Universidade Federal Rural do Semi-Árido (UFERSA), na cidade de Mossoró/RN e em seguida foram levados para o Laboratório de Proteção de Plantas, do Instituto Federal de Educação, Ciência e Tecnologia do Rio Grande do Norte (IFRN) - Campus Ipanguaçu.

As cinco amostras a serem analisadas foram submetidas à pré-secagem, para determinação da umidade. De cada amostra, $15 \mathrm{~g}$ foram levadas à estufa de circulação forçada a uma temperatura de $65^{\circ} \mathrm{C}$ por duas horas. Todos os procedimentos foram realizados em triplicatas.

\subsection{Umidade}

Usando o método de extração a seco, aproximadamente $3 g$ de pólen foram moídos e submetidos à secagem em estufa com circulação de ar a $60^{\circ} \mathrm{C}$ por 2 horas. Em seguida, foram pesadas novamente.

\subsection{Proteína Bruta}

As proteínas foram determinadas, utilizando o método Kjeldahl, pesando 0,1g de cada amostra de pólen, sendo digeridas em balão micro Kjeldahl com 1g de mistura catalítica (1:3 de $\mathrm{CuSO}_{4}$ e $\mathrm{K}_{2} \mathrm{SO}_{4}$ ) e $2 \mathrm{~mL}$ de $\mathrm{H}_{2} \mathrm{SO}_{4}$ concentrado e levadas ao digestor a uma temperatura de $350{ }^{\circ} \mathrm{C}$, por 3 horas ou até que surgiu a coloração verde translúcida.Posteriormente,com as amostras resfriadas, levou-as ao Destilador de Nitrogênio (Figura 4). A essa solução foi adicionada $10 \mathrm{~mL}$ de $\mathrm{NaOH}$ (50\%) para liberação da amônia,e esta coletada dentro de um erlenmayer com $20 \mathrm{~mL}$ de um indicador misto e ácido bórico 4\%. Sendo o indicador misto composto de $15 \mathrm{~mL}$ de verde de bromacresol e $5 \mathrm{~mL}$ de vermelho de metila. Além das amostras, foi feito o branco.

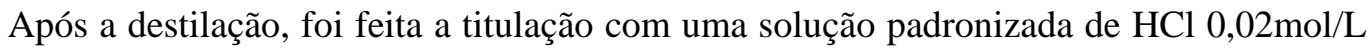
com fator de correção de 0,95 . O HCl foi padronizado com bifitalato de potássio. Para determinar as proteínas totais, foram feitos os seguintes cálculos, respectivamente: Constante $=$ N X F X 14 $\mathrm{X} 100 ; \% \mathrm{~N}=(\mathrm{VT}-\mathrm{VB}) \times$ constante/Pamostra; \%PB = \% N x 6,25.

\subsection{Lipídios}

Os lipídeos totais foram determinados pelo método de gravimetria. Foram colocados 2g de pólen moídos e extraídos com hexano à quente, em aparelho Soxhlet, por aproximadamente quatro horas.

\subsection{Cinzas}

Dois gramas de pólen foram colocados em cadinhos de porcelana e incinerados em mufla a 600 ${ }^{\circ} \mathrm{C}$, por aproximadamente quatro horas, até obtenção de cinzas brancas. Após, foi resfriado em dessecador e pesadas novamente até peso constante. O resultado final foi obtido por diferenças de pesagens (método de gravimetria) entre a massa da amostra antes e após entrada na mufla. 


\subsection{Carboidratos}

Foi calculado subtraindo-se os valores de porcentagem de cinzas, lipídeos e proteínas por 100\%. Como segue no cálculo: 100\% - (cinza + lipídios + proteínas)\%.

\subsection{Matéria Orgânica}

O valor da matéria orgânica foi obtido da subtração de 100 \% por porcentagem de cinzas (método de gravimetria).

\section{Resultados e Discussão}

Para a avaliação bromatológica do pólen apícola foram determinados os teores de lipídeos, carboidratos, cinzas, umidade e proteínas (Tabela 1).

Os teores de cinzas variaram entre 2,82 a 2,87\%, apresentando uma média de 2,84\%. Esses valores são próximos aos encontrados por Ferreira (2012), o qual identificou um percentual de 2,14 \% no Estado da Bahia e por Carpes (2008), na Região Sul, encontrando 2,87\%. Os valores de cinzas sofrem esta variação, geralmente, por as abelhas não realizarem a coleta do pólen floral apenas de uma espécie de planta.

Quanto ao conteúdo de lipídios, observou-se uma variação entre 1,71 a 3,72 \%, com uma média percentual de 2,74\%, estando de acordo com a Normativa do Mapa (2001), que estabelece um percentual mínimo de 1,8\%.A porcentagem de lipídeos nas amostras foi similar ao encontrado por Ferreira (2012), em Camaçari/BA e por Pinto et al (2012), em Taubaté - São Paulo, com teores de 2,5 e 2,8 \%, respectivamente. Valores um pouco mais elevados já foram encontrados por Carpes (2008), 4,86\%, Arruda (2009), 5,19\% e Martins (2010), 7\%.

Tabela 1 - Valores médios de cinzas, proteínas, carboidratos e lipídios em amostras de pólen apícola do Semiárido Potiguar.

\begin{tabular}{cccccc}
\hline Amostras & $\begin{array}{c}\text { Cinzas } \\
\mathbf{( \% )}\end{array}$ & $\begin{array}{c}\text { Proteínas } \\
\mathbf{( \% )}\end{array}$ & $\begin{array}{c}\text { Carboidratos } \\
\mathbf{( \% )}\end{array}$ & $\begin{array}{c}\text { Umidade } \\
\mathbf{( \% )}\end{array}$ & $\begin{array}{c}\text { Lipídios } \\
\mathbf{( \% )}\end{array}$ \\
\hline 1 & 2,82 & 12,93 & 81,84 & 24,40 & 2,41 \\
2 & 2,85 & 13,43 & 80,98 & 26,00 & 2,74 \\
3 & 2,87 & 14,25 & 79,36 & 25,70 & 3,52 \\
4 & 2,84 & 11,93 & 83,52 & 17,40 & 1,71 \\
5 & 2,83 & 12,25 & 81,58 & 19,20 & 3,34 \\
\hline Média & 2,84 & 12,95 & 81,45 & 22,54 & 2,74 \\
\hline
\end{tabular}

Fonte: MELO (2015).

Em relação à umidade do pólen in natura, os valores ficaram compreendidos entre 17,40 e 26,00 \%, apresentando uma média de 22,54\% Thomasi (2010) identificou um percentual de 15,1\%, Marchini (2006) 23,6\% e Rocha (2013) obtiveram variações entre 15 e 17\%, nos Estados de Santa Catarina, São Paulo e Trás-os-Montes em Portugal.

BRASIL (2001) estabelece que a quantidade de proteínas no pólen apícola deve ser no mínimo 8\%. As médias obtidas em trabalhos de Modro (2007) foram de 28,27\% e 23,73\%. Arruda (2009) também analisou amostras de pólen apícola de regiões do estado de São Paulo e verificou médias aproximadas como 23,42\% de proteínas. Neste trabalho, os teores variam entre 11,93 e 14,25 \%, apresentando uma média de 12,95, devido a variedade polínica das flores.

Para os valores de carboidratos foi quantificada uma média de $81,45 \%$, variando entre 79,36 e 83,52\%. Estes apresentaram correlação com a porcentagem descrita por Modro et al (2007), que obteve médias entre 61,7\% e 73,89\% nas amostras de pólen de Minas Gerais. Barreto et al (2012) identificou em amostras de pólen apícola de São Paulo, médias de 22,2\% e 41,0\% de carboidratos . Grade parte dos carboidratos constituintes no pólen apícola se deve ao néctar e o mel, os quais são misturados pelas abelhas para formarem os grãos. Este valor encontrou-se um pouco a cima dos limites estabelecidos pelo MAPA, o que é justificado pela diversificação das espécies florais da região, visto que é o fator de maior influência para a qualidade e composição química do pólen (MARTINS, 2010). 
Quanto ao teor de matéria orgânica, observou-se uma média de 97,16\%enquanto que de matéria inorgânica (2,84\%) (Tabela 2). Modro et al (2007) identificou valores quase idênticos, 97,17\% de matéria orgânica e 2,83\% de matéria inorgânica.

Tabela 2 - Valores de matéria orgânica e inorgânica apresentados no pólen apícola do Semiárido potiguar.

\begin{tabular}{ccc}
\hline Amostras & Matéria orgânica (\%) & Matéria inorgânica (\%) \\
\hline $\mathbf{1}$ & 97,18 & 2,82 \\
$\mathbf{2}$ & 97,15 & 2,85 \\
$\mathbf{3}$ & 97,13 & 2,87 \\
$\mathbf{4}$ & 97,16 & 2,84 \\
$\mathbf{5}$ & 97,17 & 2,83 \\
\hline Média & 97,16 & 2,84 \\
\hline
\end{tabular}

Fonte: MELO (2015).

\section{Conclusão}

As médias dos teores de lipídeos, proteínas, umidade e cinzas estão de acordo com a normativa do MAPA que estabelece os valores de nutrientes para pólen apícola.

O conteúdo de carboidratos obteve uma pequena variação na sua média, esta é a única análise com valores acima dos limites máximos estabelecidos pelo MAPA.

A quantificação de matéria orgânica e inorgânica também se encontrou de semelhante a demais estudos.

Com esses resultados é possível concluir que o pólen apícola da região do Semiárido pode ser considerado um alimento rico em nutrientes e dentro dos padrões para consumo humano.

\section{CHEMICAL ANALYSIS OF BEE POLLEN OF SEMI-ARID REGION}

Abstract:

The bee pollen is formed by the assemblage of pollen from flowers with nectar and salivary substances of bees. Its composition varies from floral species, nutritional status of the plant, climate and region. The bee pollen has a chemical composition that is as a food rich nutritional value that benefits health, possessing carbohydrates, lipids, proteins, vitamins and minerals. In Brazil, their identity and quality are established by the Ministry of Agriculture and Supply. With the aim of evaluating some characteristics that make bee pollen a healthy food for human consumption, the characteristics were analyzed (ash, moisture, protein, carbohydrates, lipids and organic matter) of five samples of bee pollen Natal. The average levels were: ash (2.84\%), proteins $(12.95 \%)$, carbohydrates $(81.45 \%)$, moisture $(22.54 \%)$ and lipids $(2.74 \%)$. The organic matter content was $97.16 \%$. The analyzes, almost all are in accordance with the rules of the Ministry of Agriculture and Supply in its rules No. 03 of 2001 and with studies from other regions, except for carbohydrates that are found above the maximum set value (maximum 55\%), result may be associated floral pollen diversity.

Keywords: Food; chemical composition; quality.

\section{Referências Bibliográficas}

ARRUDA, Vanilda Aparecida Soares de. Estabilidade de Vitaminas do Complexo B em Pólen Apícola. 2009. 121f. Dissertação (Ciência dos Alimentos) - Faculdade de Ciências Farmacêuticas, Universidade de São Paulo, São Paulo, 2009.

BARRETO, Lídia Maria Ruv Carelli; NORDI, João Carlos; DIB, Ana Paula da Silva; SILVA, Valter; ALVARELI, Lisa Gomes; NORDI, Nicholas Taborda, CANELA, Júlia Bertoletti. Qualidade físico-química do pólen apícola produzido no Vale do Paraíba-SP. Revista Biociências, Taubaté, v.18, n.spe, p.64-70, dez. 2012. 
BARTH, Ortrud Monika. Melissopalynology in Brazil: A Review of Pollen Analysis of Honeys, Propolis and Pollen Loads of Bee. Science Agriculture, Piracicaba, v.61, n.3, p.342-350, may./jun. 2004.

BRASIL. Ministério de Agricultura e do Abastecimento. Instrução Normativa no3, de 19 de janeiro de 2001. Regulamento Técnico de Identidade e Qualidade do Pólen Apícola. Diário Oficial da União [da] Republica Federativa do Brasil, Brasília, 23 de jan. 2001, Seção 16-I, $18-23$.

CARPES, Solange Teresinha. Estudos das características físico-químicas e biológicas do pólen apícola de Apismellifera $\boldsymbol{L}$. da região Sul do Brasil. 2008. 255f. Tese (Tecnologia de Alimentos) - Setor de Tecnologia, Universidade federal do Paraná, Curitiba, 2008.

CARVALHO, Renan Gomes. ApisMellifera: reprodução, polinização e produção de mel. 2010. 36f. TCC (Bacharelado e Licenciatura em Ciências Biológicas) - Curso Ciências Biológicas, Faculdades Integradas Fafibe, Bebedouro, 2010.

COELHO, Márcia de Souza; SILVA, José Humberto Vilar da; OLIVEIRA, Elton Roger Alves de; ARAÚJO, José Anchieta de; LIMA, Matheus Ramalho de. Alimentos Convencionais e Alternativos para Abelhas. Revista Caatinga, Mossoró, v.21, n.1, p.-1-09, jan./mar. 2008.

FERREIRA, Rodrigo da Cruz. Avaliação das características físico-químicas e microbiológicas do pólen Melipona scutellaris Latreille submetido a diferentes processos de desidratação. 2012. 105f. Dissertação (Mestrado em Ciência de Alimentos) - Faculdade de Farmácia, Universidade Federal da Bahia, Salvador, 2012.

HERVATIN, Heloisa Litholdo. Avaliação Microbiológica e Físico-Química do Pólen Apícola in natura e Desidratado sobre Diferentes Temperaturas. 2009. 99f. Dissertação (Mestrado em Ciência de Alimentos) - Faculdade de Engenharia de Alimentos, Universidade Estadual de Campinas, Campinas, 2009.

MARCHINI, Luíz Carlos; REIS, Vanderlei Doniseti Acassio dos; MORETI, Augusta Carolina de Camargo Carmello. Composição físico-química de amostras de pólen coletado por abelhas Africanizadas Apismellifera (Hymenoptera: Apidae) em Piracicaba, Estado de São Paulo. Ciência Rural, Santa Maria, v.36, n.3, p.949-953, mai./jun. 2006.

MARTINS, Márcia Cristina Teixeira. Pólen apícola brasileiro: valor nutritivo e funcional, qualidade e contaminantes inorgânicos. 2010. 236f. Tese (Doutorado em Ciência de Alimentos) - Faculdade de Engenharia de Alimentos, Universidade Estadual de Campinas, Campinas, 2010.

MENEZES, Jeane Denise de Souza. Compostos bioativos do pólen apícola. 2009. 63f. Dissertação (Mestrado em Ciências de Alimentos) - Faculdade de Farmácia, Universidade Federal da Bahia, Salvador, 2009.

MODRO, Anna F. H; SILVA, Izabel C; LUZ, Cynthia F. P; MESSAGE, Dejair. Analysis of pollen load based on color, physicochemical composition and botanical source. Annals of the Brazilian Academy of Sciences, n.81 (2), p.281-285, 2009.

MODRO, Anna Frida Hatsue; MESSAGE, Dejair; LUZ, Cynthia Fernandes Pinto da; NETO, João Augusto Alves Meira. Composição e qualidade de pólen apícola coletado em Minas Gerais. Pesquisa Agropecuária Brasileira, n.8, v.42, p.1057-1065, Brasília, 2007.

MOURA, Joelma; PEGORARO, Adhemar. Produção de pólen apícola com coletor nos horários de disponibilidade de alimento no pico da florada da Bracatinga (Mimosa scabrella). Scientia Agraria, vol.7, n.1-2, p.97-100, 2006. 
MURADIAN, Almeida Lígia Bicudo. Controle da qualidade do pólen apícola desidratado. In: XIII Congresso Brasileiro de Apicultura, 2000, Florianópolis. Anais... Santa Catarina, 2000.

PINTO, F. A; CAMPOS, C. N; BARRETO, L. M. R. C. Perfil físico-químico do pólen apícola produzido em Taubaté, Vale do Paraíba, sudeste do Brasil. Archivos Latinoamericanos de Producción Animal, vol.20, n.1-2:1-6, 2012.

ROCHA, Joana Filipa Monteiro da. Avaliação do efeito do armazenamento na qualidade do pólen apícola. 2013. 111f. Dissertação (Mestrado em Qualidade e Segurança Alimentar) - Escola Superior Agrária, Instituto Politécnico de Bragança, Bragança, 2013.

RODRIGUES, Adriana Evangelista. Produtos apícolas: Avanços na produção e comercialização. Congresso Nacional de Zootecnia, Paraíba: Centro de Ciências Agrárias/UFPB, 2006. Anais... Paraíba: Universidade federal da Paraíba, 2006.

RODRIGUES, Francimária; RIBEIRO, Maria de Fátima; SILVA, Renata Carla Santos. Produção de pólen por abelhas melíferas (Apismellifera) em área de cultivo de manga (Mangifera indica L.) no projeto irrigado de Maniçoba, Juazeiro-BA. In:CONGRESSO NORDESTINO DE PRODUÇÃO ANIMAL, 8, 2013. Fortaleza: UEVA/GEC/SNPA/EMBRAPA, 2013, p.1-3.

SCHULTE, Franziska; LINGOTT, Jana; PANNE, Ultich; KNEIPP, Janina. Chemical Caracterization and Classification of Pollen. Analytical Chemistry, v.80, n.24, dec. 2008.

SOUZA, Rosa Cristina da Silva; YUYAMA, Lucia Kiyoto Ozaki; AGUIAR, Jaime Paiva Lopes; OLIVEIRA, Francisco Plácido Magalhães. Valor nutricional do mel e pólen de abelhas sem ferrão da região amazônica. ACTA Amazônica, vol.34(2), 2004, p. 333-336.

THOMASI, Tamires Minatto. Verificação dos parâmetros físico-químicos em amostras de pólen apícola. 2010. 14f. Monografia (Curso de Farmácia) - Universidade do Extremo Sul Catarinense, UNESC, Criciúma, 2010.

VINCENZI, Vladimir Marques. O pólen apícola como elemento potencializador dos efeitos advindos da atividade física orientada em idosas. 2004. 105f. Dissertação (Mestrado em Agrossistemas) - Centro de Ciências Agrárias, Universidade Federal de Santa Catarina, Florianópolis, 2004. 